\title{
Between a frightening Present and a disjoined Future. Recession and social vulnerability in the case of Greek Neets: Socio- demographics, facets of the Crisis' Impact and the revival of the intergenerational transmission of poverty.
}

\author{
Nikos Papadakis \\ Professor, Deputy Director of the Centre for Research \& Studies \\ of the University of Crete (C.R.S./ UoC) \\ Department of Political Science, University of Crete \\ Gallos Campus, GR- 74100, Rethymnon, Greece
}

\author{
Maria Drakaki \\ PhD Candidate, Researcher at the Centre for Political Research \& Documentation \\ Department of Political Science, University of Crete \\ Gallos Campus, GR- 74100, Rethymnon, Greece
}

\begin{abstract}
Argyris Kyridis
Professor, School of Early Childhood Education, Aristotle University of Thessaloniki

University Campus - Education Faculty Tower (Thessaloniki City Centre), GR- 54124,

Thessaloniki
\end{abstract}

Antonis Papargyris

Senior Researcher at the Greek Pubic Opinion (GPO)

GPO Ltd, Nea Smyrni, GR- 171 24, Athens

\begin{abstract}
The paper initially approaches definitional issues and proceeds in a brief overview of the state of play concerning NEETs (young people not in education, employment or training) in the EU, emphasizing the relation between youth unemployment and NEET rates. Then, based on some of the key findings of a recent quantitative research (carried out within the framework of the EEA Grants/ GR07-3757 Project), the paper maps Greek NEETs' main characteristics today and presents findings related to the impact of the crisis in both Young people in total and NEETs' life course, employability, public trust, civics and survival strategies. The research leading to several of the results presented in the present paper has received funding from the EEA/Norwegian Financial Mechanism 2009-2014, under the Project Contract ${ }^{\circ}$ EEA Grants/ GR073757 ('Neets2'). The Project was carried out by the Centre for Educational Policy
\end{abstract}

\footnotetext{
1 Prof. Nikos Papadakis was the Team Leader of the EEA- funded 'Neets2' Project. Maria Drakaki was a Key Researcher at the 'Neets2' Project. Prof. Argyris Kyridis was the Deputy Team Leader of the 'Neets2' Project, on behalf of the KANEP/ GSEE. Antonis Papargyris was a Key Researcher at the 'Neets2' Project. The present paper is based on a recent Research Paper, yet it focuses on specific issues and extends its analysis on them. The abovementioned research Paper is the following: Papadakis, N. in cooperation with Maria Drakaki, Antonis Papargyris, Vassilis Dafermos, Maria Basta, Panagiotis Theodorikakos, Prokopis Pandis, Argyris Kyridis (2017), "Painted from life...." A disengaged youth? Young people and NEETs in a devastated country. Published by the UCLIoe/ Centre for Learning and Life Chances in Knowledge Economies and Societies (LLAKES). London: UCL- IoE/ LLAKES Research Centre (Research Papers Series no 59).
} 
Development of the General Federation of Greek Workers (KANEP/GSEE) (Project Coordinator Partner), the Centre for Political Research \& Documentation of the Department of Political Science at the University of Crete (KEPET/ UoC) and the Centre for Human Rights of the Department of Political Science at the University of Crete (KEADIK/UoC) (Project Partner 1). It was carried out from 15/12/2015 to 14/12/2016.

Keywords: NEETs, recession, youth unemployment, social vulnerability.

\section{PRELIMINARY REMARKS AND DEFINITIONAL ISSUES}

As Ralston, Feng, Everington and Dibben [2016] point out "NEET is a contested concept in the literature. However, it is consistently used by policy makers and shown in research to be associated with negative outcomes" [Ralston, Feng, Everington \& Dibben, 2016].

The NEET indicator corresponds to the percentage of the total population of a given age group and sex that is not employed and not involved in education or training. The age, used in the indicators, varies. Eurostat uses an indicator which covers the 15-24 years age olds [European Commission, 2011 as cited in Eurofound 2012: 22], while the OECD use a measure covering 15 to 29 year olds [OECD, 2013: 326]. The term NEET in most European countries refers to young people aged 15-24 [Eurofound, 2012: 20]. It is worth mentioning that "while the youth unemployment rate refers just to the economically active members of the population who were not able to find a job, the NEET rate can be understood as the share of the total population of young people who are currently not engaged in employment, education or training" [Eurofound, 2012: 23]. It seems that specific groups have an increased probability of becoming NEETs, including those 'with low levels of education, an immigration background, some level of disability or problems of mental health as well as young people with a problematic family background' [Eurofound, 2012: 55-56]. There is obviously a heterogeneity within the NEETs category/group [Papadakis, Kyridis, Papargyris, 2015: 47]. Specifically, that heterogeneity is related to individuals' different socio-demographic characteristics and family background in combination with the heterogeneity of the countries. As Eurofound [2016] points out "since its inception, the NEET concept has proved a powerful tool in enhancing understanding of young people's vulnerabilities in terms of labour market participation and social inclusion. As arguably the best proxy to measure the extent of young people's disadvantage, the NEET indicator can integrate subgroups such as young mothers and young people with disabilities - groups particularly at risk of being marginalised under the traditional 'inactive' label - into the policy debate" [1].

\section{NEETS IN THE EU: TRENDS AND DATA}

The term NEET, initially appeared in the 1990s, in the UK, "is now centrally embedded in the policy discourse of the European Commission, the European Parliament and the Council of the European Union" [Eurofound, 2016: 1]. It should be noted that NEETs rate is substantially interrelated to the youth unemployment rate, even it substantially differs, since the focus on NEETs, ex definitio "highlights the problem of 'inactive youth', together with the young unemployed, but it draws attention away from those who are employed but trapped in inferior types of job" [Bardak, Rubal Maseda, Rosso/ ETF, 2015: 7]. The rate of NEETs (aged 15 to 24) in the EU28 reached 13\% in 2013, while it was just 10.9\% in 2008 [Eurostat, EU-LFS data [edat_lfse_20] as cited in European Commission, 2015: 17]. The share of the NEET population varies among EU Member States. In Greece, Italy and Bulgaria the NEET rate exceeded 20\% in 2013 [Eurostat, 2017a]. The rate for NEETs in the EU has gradually decreased since 2013, yet remains higher $(12 \%$ in 2015$)$ than it was before the onset of the economic crisis [European Commission, 2015: 17]. NEETs rate variations resemble the one of the youth unemployment rate, since "in 2013, some 23.5\% of young people (aged 15-24 years) across the EU were unemployed, the highest level ever recorded in the history of the EU. During the crisis, 18 
Papadakis, N., Drakaki, M., Kyridis, A., \& Papargyris, A. (2017). Between a frightening Present and a disjoined Future. Recession and social vulnerability in the case of Greek Neets: Socio-demographics, facets of the Crisis' Impact and the revival of the intergenerational transmission of poverty. Advances in Social Sciences Research Journal, 4(18) 8-20.

Member States recorded their highest-ever levels of youth employment [Eurofound, 2014: 2]. The youth unemployment rate decreased markedly in 2014 and 2015 in comparison with 2013. In 2015, the EU youth unemployment rate was $20.3 \%$. This decrease was consolidated over the course of 2016. In February 2016, the youth unemployment rate was 19.4\%, the lowest level since April 2009" [Eurofound 2016: 5]. Indeed, in the vast majority of the EU countries, the rise in rates for NEETs was a consequence of the increase of youth unemployment, rather than inactivity. Specifically, in Greece, Spain and Croatia around 70\% of NEETs were unemployed but active in 2014, while in Bulgaria, Romania and Italy the majority of NEETs were inactive [European Commission, 2015: 48]. However, the majority of inactive NEETs, are 'discouraged workers'. Namely, they believe that there is no available job for them [Eurofound, 2012: 33]. This fact implies that there are structural barriers in relation to young population's transition and inclusion in the labour market or in education [Eurofound, 2016: 20]. In countries such as Bulgaria, Greece, Cyprus, Spain, Italy, Croatia and Romania the NEET rate increased considerably since the beginning of the crisis until 2015, not least due to increases in youth unemployment. In 2015, the NEET rates in these countries were 19.3\%, $17.2 \%, 15.3 \%, 15.6 \%, 21.4 \%, 18.5 \%$ and $18.1 \%$ respectively [Eurostat, 2017a] (see Figure 1).

Figure 1: NEET rates in Europe (2015) (aged 15-24)

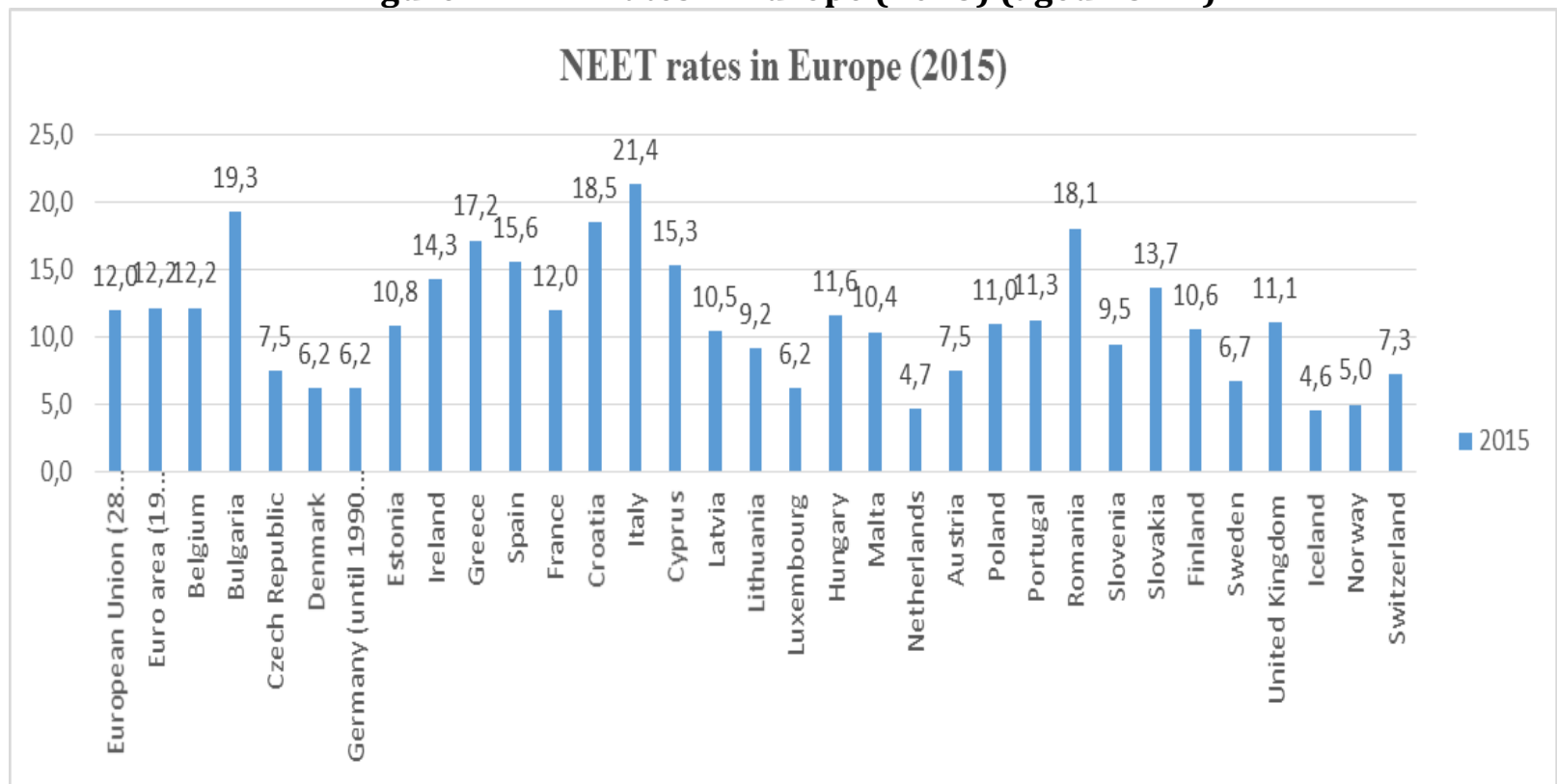

Source: Eurostat, 2017a:

http://ec.europa.eu/eurostat/tgm/table.do?tab=table\&init=1\&language=en\&pcode=tesem 150 \&plugin=1.

It should be noted at this point, that given that the NEETs rate reflects the share of young people not in education, employment or training in the total corresponding population (and not just the economically active ones, such as in the case of unemployment), the NEET population (12\% in the EU28) was 6.604 .000 in 2015, while the Youth Unemployment Rate, even higher (namely 20.3\%) corresponded to 4.641 .000 young people [Eurofound 2016: 1011]. That quantitative data highlight the extent of the challenge, set to the public policy agenda by the phenomenon of NEETs.

\section{YOUNG UNEMPLOYMENT AND YOUNG PEOPLE NOT IN EDUCATION, EMPLOYMENT OR TRAINING IN GREECE.}

Undoubtedly, Greece is an economically and socially weakened country [see analytically Papadakis et al, 2017], heavily affected by the Crisis and Recession. The impact of the ongoing 
crisis in Greek employment was huge and persistent. Unemployment has risen from 7.8\% in 2008 [Eurostat, 2017b] to 27.5\% in 2013, with 1319562 people being unemployed in December 2013 [HSA, 2017a: 2]. Since the onset of the crisis, unemployment in Greece remains extremely high, even slightly decreasing since 2014 . While total unemployment in the EU28 dropped to 8.1\% in January 2017 (its lowest level since 2009 and 0.8 percentage points lower in January 2016), total unemployment in Greece was still 23\% in November 2016, [Eurostat, $2017 \mathrm{c}]$. In addition, at the $3^{\text {rd }}$ quarter of 2016, the long-term unemployment rate in Greece reached 16.7\%, over four times the level for the EU28 [Eurostat, 2017c; Eurostat, 2017d]. In 2011, Matsaganis [2011] claimed that "the rise in unemployment is likely to be transformed into higher poverty, while in the past the correlation between the two has been rather weak" [510]. Indeed, this is what actually happened within the forthcoming years. In $2015,21.4 \%$ of the Greek population was living under the poverty limit, while $35.7 \%$ was at risk of poverty or social exclusion, according to the Hellenic Statistic Authority [HSA, 2016: 1-2]. Youth unemployment is explicitly related to poverty-risk and social exclusion. Even though no social group in Greece has been unaffected by the crisis, which left a quarter of economically active adults unemployed and about a third in poverty, at the $4^{\text {th }}$ quarter of 2016 [see in detail HSA, 2017b: 108-114, 126-127; Papadakis et al, 2017: 11], the impact of the crisis on the new generation is particularly worrying, multi-parametric and mainly insisting.

The case of NEETs confirms the abovementioned argument. Greece, before the onset of the crisis, had a similar proportion of young people classified as NEET as the rest of the EU. However, by 2013 the rate for NEETs had reached 20.4\% - almost double the rate for 2008 and $42 \%$ higher than the EU average (13\%). By 2015 the NEET rate was still above 17\% [Eurostat, 2017e] (see Figure 2).

Figure 2: NEET rates in Greece \& EU28 (2008-2015)

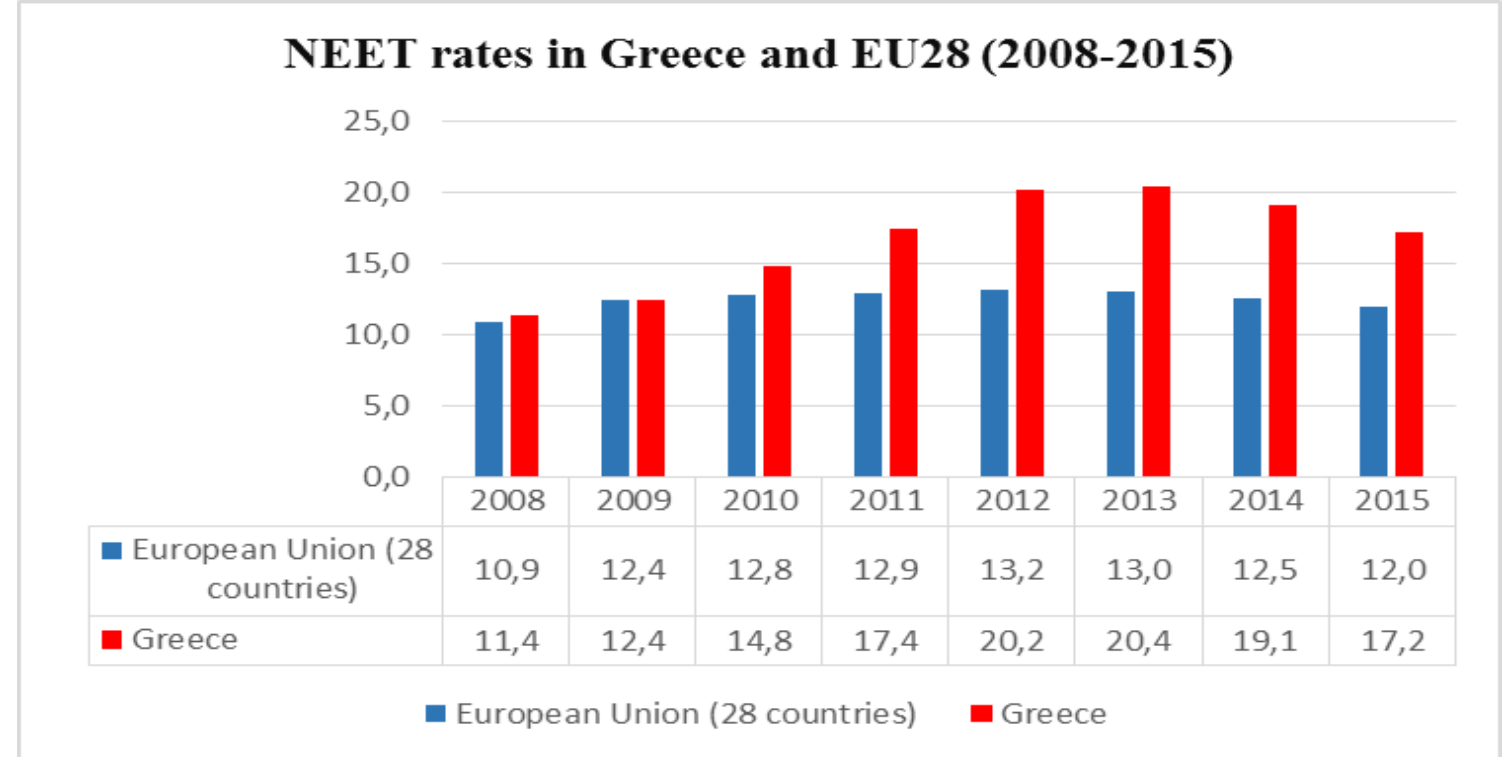

Source: Eurostat, 2017e: http://appsso.eurostat.ec.europa.eu/nui/submitViewTableAction.do.

Within the period from 2008 to 2012, the percentage of women classified as NEET in Greece was higher than that for men. In 2012 the male NEET rate was 19\%, 2.9 percentage points higher than in $2011(16.1 \%)$ and 2.3 percentage points below the corresponding female rate (21.3\%). In 2013, the female NEET rate slightly decreased to $20 \%$, while men's rate increased to $20.9 \%$. In 2014 , both NEET rates dropped (to $18.7 \%$ for men and $19.6 \%$ for women), while in 2015 the NEET rate for both men and women dropped further (to $17.1 \%$ and 17.2\% respectively) and converged [Eurostat, 2017e]. Regarding the regional dimension, Greece has witnessed a significant increase from 2011 to 2015, mainly in the regions of Thessaly, Ionian 
Papadakis, N., Drakaki, M., Kyridis, A., \& Papargyris, A. (2017). Between a frightening Present and a disjoined Future. Recession and social vulnerability in the case of Greek Neets: Socio-demographics, facets of the Crisis' Impact and the revival of the intergenerational transmission of poverty. Advances in Social Sciences Research Journal, 4(18) 8-20.

Islands, Central Greece and Peloponnese. Further, we should mention that despite the slight decrease at the country level, in island regions a mirror-image trend is evident. In 2015 the NEETs rate in Ionian Islands reached 25.5\%, rising from 19.9\% in 2014, while in South Aegean it reached to $22 \%$, rising from $14.8 \%$ in 2014 [Eurostat, 2017f]. It is clear, that there is a direct and persistent correlation between the broader impact of the crisis ${ }^{2}$ and the NEET rate, that reflects the ongoing disengagement of the youth from the labour market and the key social institutions. This disengagement arises from the impact of the economic recession on the labour market, resulting in a huge lack of jobs and, consequently, in the rapid increase of the youth unemployment rate in Greece [see in detail Papadakis, Kyridis, Papargyris, 2015: 47, 54, 58; Drakaki et al, 2014: 240-242]. Furthermore, the inadequacy of the Greek Welfare State, which has failed to protect NEETs and young people in general as well as to re-integrate them in the labour market, constitutes an additional major parameter for youth's disengagement from the labour market and the social institutions [Kotroyannos et al, 2015: 275-276], in spite of the fact that "NEETs are also at the heart of the Youth Guarantee" [Eurofound, 2016: 12] applied for Greece as well. It should be noted at this point, that - according to a previous survey- the vast majority of Greek NEETs are economically active job-seekers. Additionally they are willing to migrate either within the country or abroad in order to find a job [see Papadakis, Kyridis, Papargyris, 2015: 67-68; Drakaki et al, 2014: 247; GPO \& KEADIK, 2012: 42, 50; KEADIK \& KANEP, 2013: 20], given that the labour market has partially collapsed in the country.

\section{THE CURRENT STATE OF PLAY: RECENT RESEARCH FINDINGS ON NEETS IN GREECE TODAY}

An EEA-funded large-scale research Project entitled 'NEETs2' (EEA Grants/GR07-3757), was completed in 2016. In brief, through primary nationwide quantitative and qualitative research, the project aimed, firstly, at the research-based mapping of the relationship between Greek NEETs and psychopathology, the sketching of their psychological profile as well as the investigation of the impact of the economic crisis on their psychological profile and life course. Furthermore, it aimed at the research-based mapping of NEETs' skills profile and their needsin-skills. Within this context, the quantitative and qualitative findings led to a targeted and competences-based training-reskilling programme (including two counseling and vocational guidance handbooks) and a proposed set of psychological supportive activities towards NEETs' social inclusion in Greece. This recently completed research project, emphasized key determinants of NEETs' life course and values as well as of young people in general in Greece, including civic values, public trust, political behavior and survival strategies. Based on the stratified, quota-based, sampling (with 2769 respondents in the total of the 13 Administrative Regions), the key findings of the "NEETs2" Project were the following: the NEET rate, in May 2016, was 16.4\% of the Greek young population (aged 15-24) [KEPET \& KEADIK, 2016: 7], while NEETs, compared to our control group (namely young people 15-24 years), are older, have less age-adjusted years of education, are more likely to live with their parents, have more work experience and lower family income [see in detail Papadakis et al, 2017: 18-19]. Age seems to be a determining factor that affects a young person's chances to qualify as NEET. Following a descriptive analysis, we can document that after the age of 22 the NEET phenomenon grows exponentially and culminates at the age of 24 years, where $34.9 \%$ of people of this age are now NEETs [KEPET \& KEADIK, 2016: 7]. This allows us to conclude that the Greek family (less so the Greek society) have managed to find ways prevent the

2 The recent crisis, indeed, "has exacerbated the problem of young people's labour market participation" [Eurofound, 2016: 5]. 
marginalization of younger people, mechanisms which, however, do not cover equally efficiently older ages. The relatively low rates of early school leaving/dropout and respectively the high rates of completion of upper secondary education in Greece explain the low incidence of NEETs in the younger age groups. On the other hand, "the family protection even "unintentionally" contributes to young people's entrapment in a family enclave, which is transformed into a key tool of informal social protection, especially when the welfare State fails to actually protect,.... the traditional social enclave of family undertakes the treating of social pathologies that "occur" to its members, assuming the role of "social protector" not only where when its members cannot be protected but also acting unsolicitedly" [Papadakis, Kyridis, Papargyris, 2015: 52]. Yet, family seems to operate as an individualized policy substitute, given the deconstruction of the Welfare State, preventing the total disruption of NEETs' life course.

Recent surveys document that "results also show that negative NEET effects are variable when stratifying by educational attainment and are different for men and women". The education level is a key variable in surveys on Neets [Ralston, Feng, Everington \& Dibben, 2016]. Given that and regarding the education level of the young people in Greece, we should mention that almost 1 out of 4 young people (aged 15-24) is high skilled. 27.4\% of the Greek NEETs are Higher Education graduates (clearly more than their peers-21.1\%), namely more than 1 out of 4 NEETs is high skilled in Greece, Indeed, this is an alarming finding, especially given the fact that in the majority of the EU countries, NEETs are usually low or medium skilled [Eurofound, 2012: 31; Eurofound, 2016: 2] (see Figures 3-4).

Figure 3: The Education Level Greek Youth (22.1\% HE Graduates)

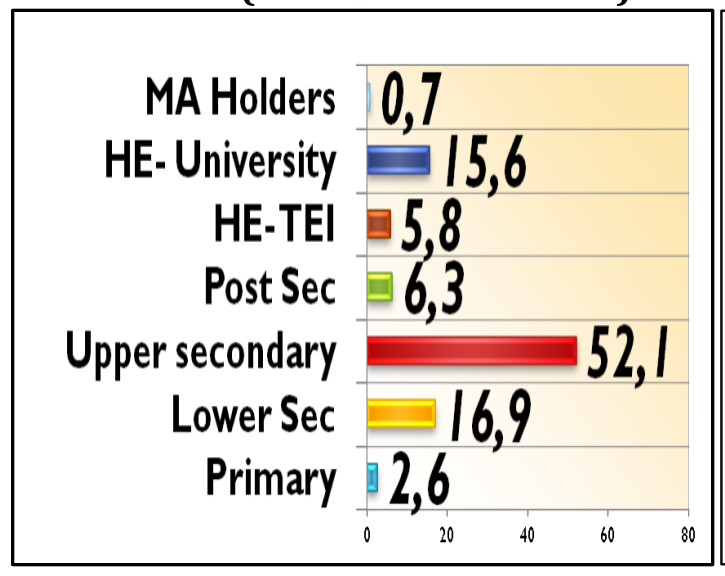

Source: KEPET \& KEADIK, 2016: 12.
Figure 4: The Education Level of NEETs of the

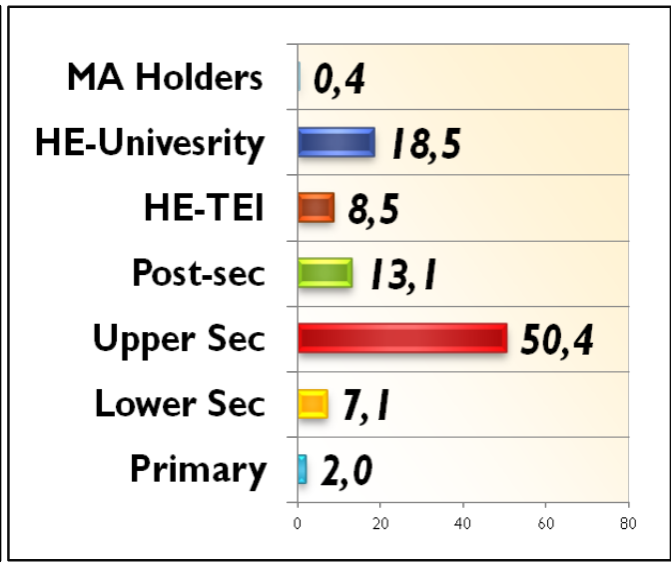

Source: KEPET \& KEADIK, 2016: 12.

When it comes to family income, it should be noted that the majority of both the youth as such and the NEETs live in households with low or very low income. This finding is of particular interest. Further analysis, documents that NEETs are usually members of families with a lower income than their peers. We can, therefore, state that the family income is a decisive determining factor that increases a young person's chances to fall in the NEET category [Papadakis et al, 2016: 36-37]. In other words, the lower the monthly family income is, the greater the risk of social exclusion becomes. This formulates a vicious cycle since previous research findings in other contexts have revealed a strong relationship between NEET status and income, while long- term unemployment is usually associated to lower income [Gregg \& Tominey, 2005]. There is no doubt, that NEET status in Greece is more frequent among lower socio-economic levels/ groups (with less age-adjusted years of education and lower family income).What is even more alarming is the fact that approximately $40 \%$ of the Greek young people live in households, whose monthly income is less than $1000 €$ (see Figure 5). The above-mentioned findings further confirm the hypothesis of intergenerational transmission of 
poverty in Greece today [Papatheodorou \& Papanastasiou, 2010; Papadakis, Kyridis, Papargyris, 2015: 56].

Figure 5: Family Income of NEETs

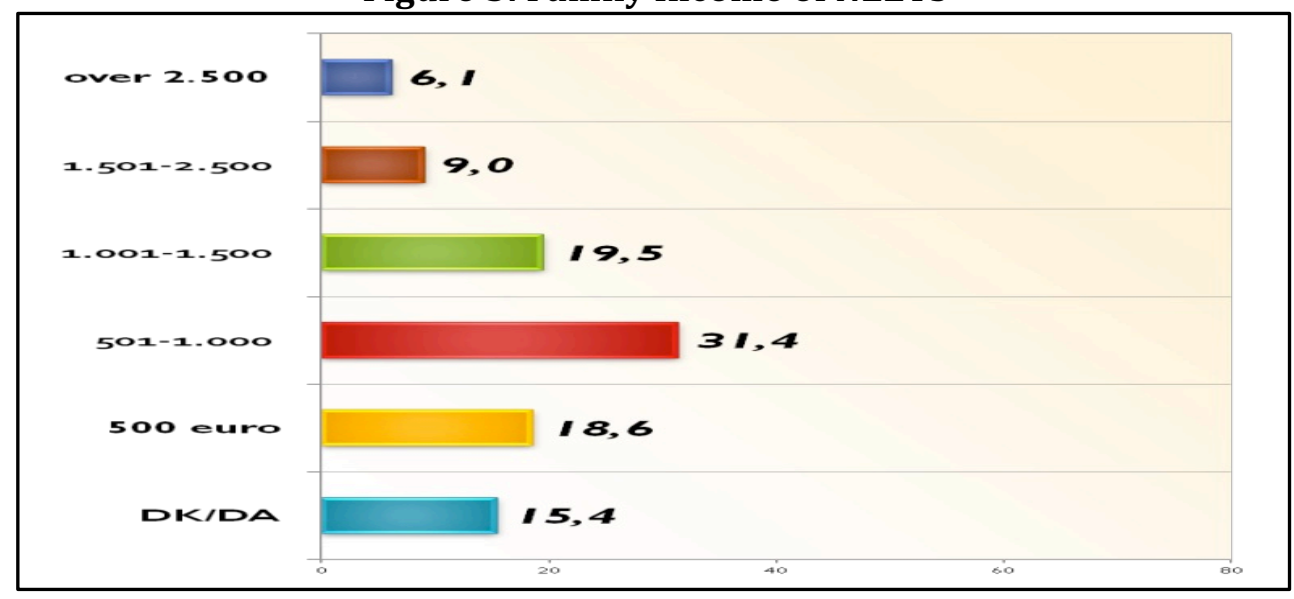

Source: KEPET \& KEADIK, 2016: 19.

The self-definition of the individual condition by the young people in Greece is not surprising. $30.8 \%$ of the young people and $45.8 \%$ of NEETs in Greece describe their situation as hard and unbearable [KEPET \& KEADIK, 2016: 26] (see also Figure 6). Thus, 1 out of 3 young people in Greece and half the NEETs face severe difficulties in their daily life. The significant variation of 17.9 percentage points between NEETs and their peers [KEPET \& KEADIK, 2016: 32] demonstrates the strong psychological impact caused by the marginalization of young people and their alienation from the labour market and the educational process.

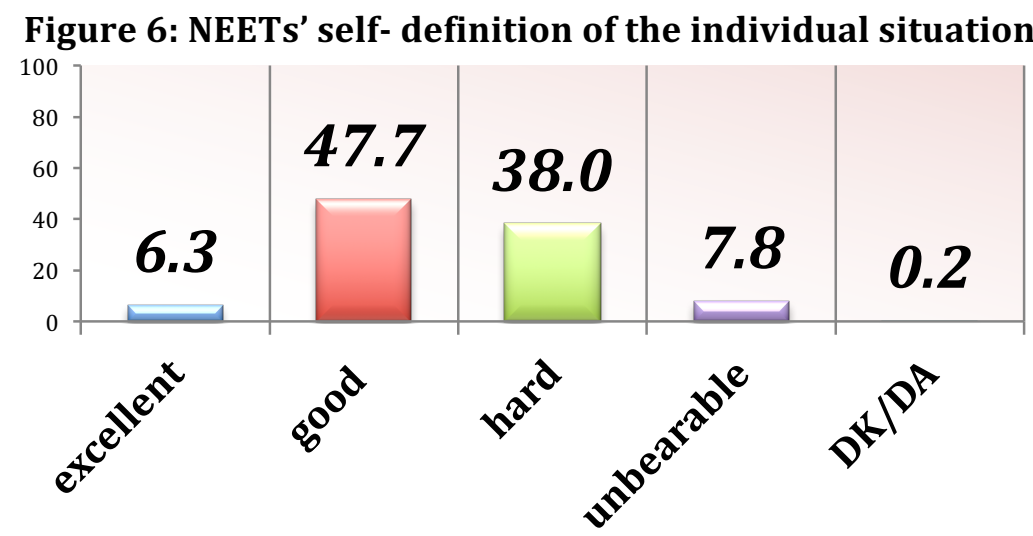

Source: KEPET \& KEADIK, 2016: 32.

In terms of employability, it should be primarily noted that the majority of young people and the vast majority of NEETs have prior working experience [KEPET \& KEADIK, 2016: 13]. NEETs, coming from families with lower income, were more forced to enter earlier the labour market, yet all of the $73.6 \%$ of them who have prior work experience are now unemployed. It is a crystal clear effect of the persisting crisis. The following findings make it self-evident. The vast majority of the NEETs (84.3\%) as well as of their peers (79\%) have lost their jobs during the last 2 years (see Figure 7). The vast majority of young people (including NEETs) who has prior working experience, gained it mainly in the tertiary sector. Mainly, NEETs usually have previous work experience, due to seasonal employment (catering, leisure and tourism). Given that, we could presume that the ones, who are recently unemployed, belong to the category of seasonal employment. However, $32.7 \%$ of the young population and $39.7 \%$ of the NEETs, being 
before employed, have lost their jobs more than 6 months and less than 2 years ago. That's not the case for seasonal employment. Within the age group of 15-24 with prior work experience, the majority are men $20-24$ years old. $44 \%$ of the young people $(26.4 \%$ of NEETs and $47.8 \%$ of their peers) have not ever entered the labour market. 26.1\% (26.3\% of NEETs) of the ones, who did it, are now long-term unemployed [see analytically KEPET \& KEADIK, 2016].

Figure 7: Unemployment period of NEETs (concerns the ones who have prior working experience)

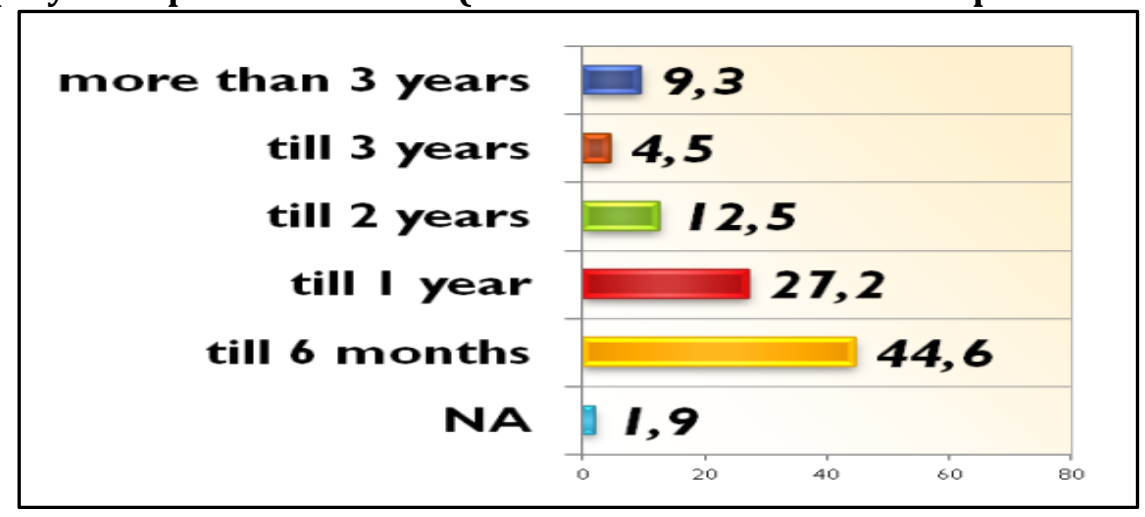

Source: KEPET \& KEADIK, 2016: 14.

Delaying entry or being disengaged from the labour market hamper, decisively, the possibility of (re)integration into employment in general and eventually feedback the vicious circle of youth unemployment. Regarding the employment status and broadly the relationship of young people (including NEETs) to employment, the research findings clearly document that the economic crisis has contributed decisively to youth unemployment, while two main taxonomic categories are formulated, grosso modo: a) those who never have worked and b) those who have worked for a while and have been laid off, either as a result of cutbacks in personnel and in other cases due to bankruptcy of the company-enterprise they were employed in, or because they were seasonal or occasional employees. Of course, it should not also be ignored the case of those who left voluntarily.

Given that training is (or at least should be) an active employment policy [see in detail Papadakis, 2005], the findings concerning training and its relation to employability are absolutely discouraging. Just $15.9 \%$ of young people $(17.7 \%$ of NEETs and $15.6 \%$ of their peers) have attended a training programme in the past. The minority of young people has attended a training programme and, among them, the vast majority considers training ineffective. It is obvious that despite unemployment, young people neither are attracted from training nor trust it at all (see Figures 8a-b). 
Papadakis, N., Drakaki, M., Kyridis, A., \& Papargyris, A. (2017). Between a frightening Present and a disjoined Future. Recession and social vulnerability in the case of Greek Neets: Socio-demographics, facets of the Crisis' Impact and the revival of the intergenerational transmission of poverty. Advances in Social Sciences Research Journal, 4(18) 8-20.

Figure 81: Evaluation of training effectiveness by the participants (whether it helped them finding a job - with regard to the ones who have attended a training program)

\section{a) Young People, in total}

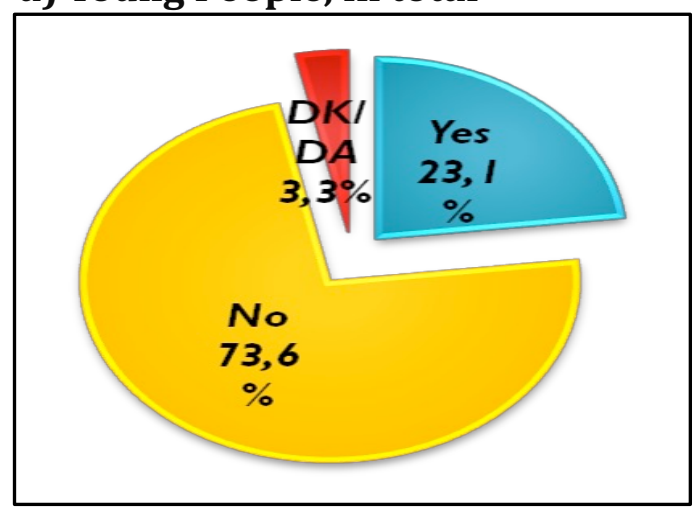

Source: KEPET \& KEADIK, 2016: 16. b) NEETS

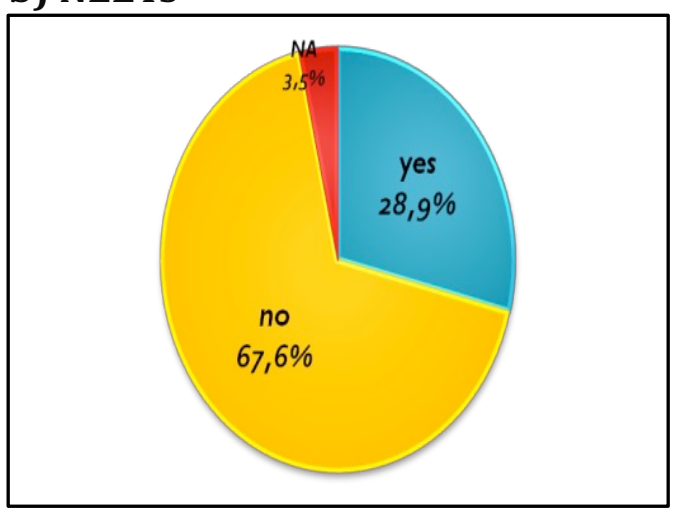

Source: KEPET \& KEADIK, 2016: 16.

Given all the abovementioned, the emotions caused to both Greek young people (in total) are not surprising. It seems that the impact of the ongoing economic recession has resulted in insecurity (48\%), anger (27\%) and anxiety (17.1\%). Almost none is optimistic (3.6\%), while there are no statically significant differences between NEETs and their peers [see in detail KEPET \& KEADIK, 2016: 35]. Yet, when it comes to the individualized perception of social exclusion, a seemingly paradox rises. The relevant findings, related to whether NEETs feel socially excluded, seem unexpected: $90.2 \%$ of NEETs do not feel socially excluded, almost equally to their peers (93.6\%) [KEPET \& KEADIK, 2016: 26]. Undoubtedly, NEETs qualify for classification as socially excluded. However, as already stated, the majority of them do not feel socially excluded. Given that, is the abovementioned finding interpretable? Definitely. In fact, this precise finding totally resembles the relevant one, within the framework of the previous research on NEETs ('Absents Barometer'/ 2011-2013). It seems that, still "the family security grid, the widening of social vulnerability that inevitably brings many young people in a similar situation with Neets, reduce the feeling of alienation and isolation" [Papadakis, Kyridis, Papargyris, 2015: 64]. Alteris verbis, NEETs are not on their own, since a lot of their peers are in similar situation. The broader troubled state of play diminishes the feeling of isolation, however it clearly documents an ongoing hardened situation for numerous young people in Greece. In other words, NEETs do not feel excluded mainly due to the fact that there are so many others suffering. The abovementioned clearly affects NEETs' priorities and survival strategies. The survey revealed a totally reverse image, in terms of life-course design, between NEETs and their peers. While job-seeking is a clear priority for NEETs (up to 60.6\%), learning process far exceeds (51.6\%) in their peers' priorities [see in detail KEPET \& KEADIK, 2016: 30]. The key choices, that young people have already done or are highly likely to do, include job seeking regardless its relation to their specialization and studies, migration abroad, changing residence (moving to another cheaper apartment or to family home) and changing even their dietary habits, by proceeding in severe cuts (see Figure 9). 
Figure 9: Young People's Survival Strategies ${ }^{3}$

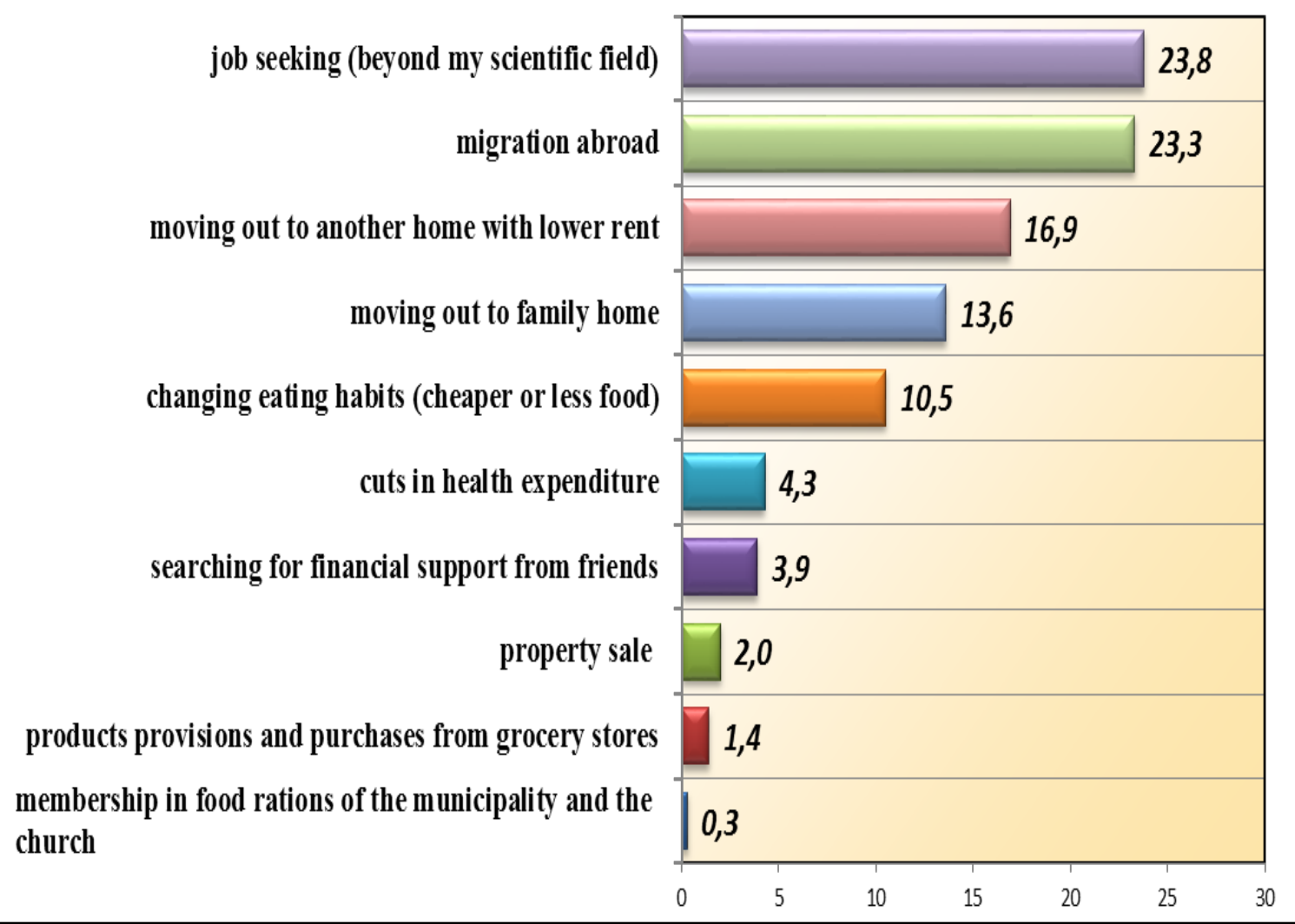

Source: KEPET \& KEADIK, 2016: 27.

It is worth mentioning, that these top-5 choices are identical both to NEETs and their peers namely the rest of the youth [KEPET \& KEADIK, 2016: 28]. Indeed, the impact of the crisis is multi-parametric, affecting substantial aspects and facets of young people's daily life.

The findings of the research project "NEETs2" are discouraging when it comes to issues of public trust and political behaviour. Public trust is collapsing among youth, while the vast majority of young people have a negative view on the political system and personnel, blaming them for their discouraging situation and the increasing difficulties that they face in their daily life [see in detail Papadakis et al, 2017: 29-33]. Further, when it comes to the degree of confidence on the Greek State in respect to the Welfare provisions, $91.4 \%$ of the Greek youth do not trust at all or trusts a little the social welfare system in Greece. This lack of confidence is equally diffuse both in NEETs and their peers. Indeed, this is a further indication of the collapse of the public trust among young people in Greece, while the rising of a 'disengaged self' is clearly and further documented by the findings related to the ideological self-definition. $39.4 \%$ of the Greek young people (42.9\% of NEETs and 38\% of their peers) feel isolated and alienated from any established ideology. In other words, they are ideologically disengaged [see Papadakis et al, 2017: 31-33; KEPET \& KEADIK, 2016: 43]. This is undoubtedly alarming.

${ }^{3} \mathrm{Q}$; Which is the most likely to do firstly or have already done of the following, as a result of the crisis?

(Young People, in total) 


\section{CONCLUSIONS}

As Andy Green [2017] points out, "the 2007/2008 financial crisis and the ensuing recession and austerity dramatized the situation of young people because they were the age group which was hardest hit in terms of rising unemployment and declining real wages" [7]. In Greece, the ongoing recession still prevails and its impact over-determines adulthood and young people' life course. In the case of young people, absent from education, employment and training (namely NEETs) things seem even worse: "facing a discouraged and devastated reality, substantially reflecting on every key aspect of their life course, young people in Greece become increasingly frustrated, pessimistic and even angry" [Papadakis et al, 2017: 32]. Indeed, in the Greek case as many others "traditional approaches that try to understand young people's vulnerabilities in terms of their transition into adulthood have become less effective [Eurofound, 2016: 5].

It seems that the extended and persistent Recession hasn't just affected young people's and mainly NEETs' employability and life course, but even more has resulted in a gradually broadening disregard of the political system and the institutions. Their trust in social and political institutions is gradually collapsing, while lack of prospects, hopeless job seeking in a disjointed labour market, social exclusion (even not perceived as such, due to the extent of social vulnerability), ineffective training and severe cuts in the Welfare provisions define their present and undermine NEETs' (and many of their peers', as well) future. Their framework of standard biography ${ }^{4}$ is subjected to an unpredictable deconstruction, since the long lasting crisis and the subsequent recession limit their future prospects and heavily affect their choices and survival- exit strategies. The family, seemingly affected by the crisis, operates as a policy substitute, since the public institutions are failing to provide reliable and viable choices (such as in the case of training). Yet is not either enough (given the intergenerational transmission of poverty) or negative effects-free -in several cases it enclaves young people- [Papadakis, Kyridis, Papargyris, 2015: 52].

A future which doesn't seem less discouraging rather the present of a gradually disengaged youth raises a clear challenge to the public institutions and the stakeholders of the Society in Large. A challenge that should, by no means, remain unresolved.

\section{References}

(G: in Greek)

Alheit, P. \& Bergamini, S. (1998). “Biographical research and life history research”, in S. Papaioannou (ed.), Social Transformation, Education and Local Community. Rethymnon: University of Crete - International Postgraduate Summer School, pp. 122-130 (G).

Atkinson, R. (1998). The life story interview. Thousand Oaks, Calif.: Sage Publications.

Bardak, U., Rubal Maseda M. \& Rosso Fr./ ETF (2015). Young people not in employment, education or training (NEET). An overview in ETF Partner Countries. Turin: European Training Foundation. Available at: http://www.etf.europa.eu/webatt.nsf/0/BFEEBA10DD412271C1257EED0035457E/\$file/NEETs.pdf.

Drakaki, M., Papadakis, N., Kyridis, A. \& Papargyris, A. (2014). “Who’s The Greek Neet? Parameters, Trends and Common Characteristics of a Heterogeneous Group”, International Journal of Humanities and Social Science, 4 (6), April 2014, pp. 240-254.

Eurofound (2012). NEETs - Young people not in employment, education or training: Characteristics, costs and policy responses in Europe. Luxembourg: Publications Office of the European Union.

Eurofound (2014). Mapping youth transitions in Europe. Luxembourg: Publications Office of the European Union.

${ }^{4}$ see in detail on this issue: Alheit \& Bergamini, 1998: 122; Atkinson, 1998. 
Eurofound (2016). Exploring the diversity of NEETs. Luxembourg: Publications Office of the European Union.

European Commission (2015). Employment and Social Developments in Europe 2014. Luxembourg: Publications Office of the European Union. Available at:

http://ec.europa.eu/social/keyDocuments.jsp?advSearchKey=Employment+and+Social+Developments+in+Europ ea $+2014 \&$ mode=advancedSubmit\&langId=en\&policyArea=\&type=0\&country=0\&year=0 (accessed 22/3/2017).

Eurostat (2017a). "Youth neither in employment nor in education and training (NEET) rate, age group 15-24, [tesem150]". Available at:

http://ec.europa.eu/eurostat/tgm/table.do?tab=table\&init=1\&language=en\&pcode=tesem $150 \&$ plugin=1 (accessed 23/03/2017).

Eurostat (2017b). “Unemployment by sex and age - annual average, [une_rt_a]”. Available at: http://appsso.eurostat.ec.europa.eu/nui/show.do?dataset=une_rt_a\&lang=en (accessed 23/03/2017).

Eurostat (2017c). "Newsrelease - Euroindicators, 34/2017 - 2 March 2017". Available at: http://ec.europa.eu/eurostat/documents/2995521/7895735/3-02032017-AP-EN.pdf/8a73cf73-2bb5-44e49494-3dfa39427469 (accessed 23/03/2017).

Eurostat (2017d). "Long-term unemployment by sex - quarterly average, [une_ltu_q]." Available at: http://appsso.eurostat.ec.europa.eu/nui/show.do?dataset=une_ltu_q\&lang=en (accessed 23/03/2017).

Eurostat (2017e). "Young people neither in employment nor in education and training by sex, age and educational attainment level (NEET rates), [edat_lfse_21]". Available at:

http://appsso.eurostat.ec.europa.eu/nui/submitViewTableAction.do (accessed 23/03/2017).

Eurostat (2017f). "Young people neither in employment nor in education and training by sex and NUTS 2 regions (NEET rates), [edat_lfse_22]". Available at:

http://appsso.eurostat.ec.europa.eu/nui/show.do?dataset=edat_lfse_22\&lang=en (accessed 23/03/2017).

GPO \& KEADIK of the Department of Political Science/Uoc (2012). “Deliverable 3.1a: Report of the NEET population in Greece, in terms of age, sex, ethnicity (immigrants without Greek nationality), urbanity, educational level and administrative region (first phase of the quantitative study)". Deliverable of the Project: 'Absents' Barometer'. Detection, categorization and empirical grounding of policy proposals for tackling a new form of social vulnerability: The NEETs (Young People Not in Education, Employment or Training), Rethymnon (G).

Green, A. (2017), The Crisis for Young People. Generational Inequalities in Education, Work, Housing and Welfare. London: Palgrave Macmillan.

Gregg, P., \& Tominey, E. (2005). The wage scar from male youth unemployment, in Labour Economics, 12(4), pp. 487-509.

Hellenic Statistical Authority (2016). "Press Release: Risk of Poverty. 2015 Survey on Income and Living Conditions (Income reference period 2014)”. 23/06/2016, HSA: Piraeus. Available at:

http://www.statistics.gr/en/statistics?p_p_id=documents_WAR_publicationsportlet_INSTANCE_qDQ8fBKKo4IN\& p_p_lifecycle $=2 \&$ p_p_state $=$ normal\&p_p_mode $=$ view $\&$ p_p_cacheability $=$ cacheLevelPage\&p_p_col_id $=$ column$2 \&$ p_p_col_count=4\&p_p_col_pos=1\&_documents_WAR_publicationsportlet_INSTANCE_qDQ8fBKKo4IN_javax.face s.resource=document\&_documents_WAR_publicationsportlet_INSTANCE_qDQ8fBKKo4IN_ln=downloadResources \&_documents_WAR_publicationsportlet_INSTANCE_qDQ8fBKKo4IN_documentID=185093\&_documents_WAR_pub licationsportlet_INSTANCE_qDQ8fBKKo4IN_locale=en (accessed 23/03/2017).

Hellenic Statistical Authority (2017a). “Press Release. Labour Force Survey: December 2016”. 9 March 2017, HSA: Piraeus. Available at:

http://www.statistics.gr/en/statistics?p_p_id=documents_WAR_publicationsportlet_INSTANCE_qDQ8fBKKo4IN\& p_p_lifecycle $=2 \&$ p_p_state $=$ normal\&p_p_mode $=$ view\&p_p_cacheability $=$ cacheLevelPage\&p_p_col_id $=$ column$2 \&$ p_p_col_count=4\&p_p_col_pos=1\&_documents_WAR_publicationsportlet_INSTANCE_qDQ8fBKKo4IN_javax.face s.resource=document\&_documents_WAR_publicationsportlet_INSTANCE_qDQ8fBKKo4IN_ln=downloadResources \&_documents_WAR_publicationsportlet_INSTANCE_qDQ8fBKKo4IN_documentID=234702\&_documents_WAR_pub licationsportlet_INSTANCE_qDQ8fBKKo4IN_locale=en (accessed 23/03/2017).

Hellenic Statistical Authority (2017b). Greece in Figures. October - December 2016. HSA: Piraeus. Available at: http://www.statistics.gr/documents/20181/1515741/GreeceInFigures_2016Q4_EN.pdf/b6478000-34ca-4ac5b6e8-a02ed096ba97 (accessed 22/03/2017).

KEADIK of the Department of Political Science/UoC \& KANEP/GSEE (2013). D4.4b: Report on the final findings (of the qualitative research) and thematic categories. Deliverable of the Project: 'Absents' Barometer'. Detection, categorization and empirical grounding of policy proposals for tackling a new form of social vulnerability: The NEETs (Young People Not in Education, Employment or Training), Rethymnon (G). 
Papadakis, N., Drakaki, M., Kyridis, A., \& Papargyris, A. (2017). Between a frightening Present and a disjoined Future. Recession and social vulnerability in the case of Greek Neets: Socio-demographics, facets of the Crisis' Impact and the revival of the intergenerational transmission of poverty. Advances in Social Sciences Research Journal, 4(18) 8-20.

KEPET \& KEADIK of the Department of Political Science, Uoc/ Papadakis, N., Papargyris, A. \& Dafermos, V. (2016). D3.2. Report on the impact of the financial crisis to the abovementioned (based on the quantitative research at national level). Rethymnon: Deliverable of the Project "NEETs2" (EEA-Grants GR07/3757 - unpublished) (G).

Kotroyannos, D. Lavdas, K. A., Papadakis, N., Kyridis, A., Theodorikakos, P., Tzagkarakis, S. I., \& Drakaki, M. (2015). An Individuality in Parenthesis? Social Vulnerability, Youth and the Welfare State in Crisis, Studies in Social Sciences and Humanities, 3 (5), pp. 268-279.

Matsaganis, M. (2011). The welfare state and the crisis: the case of Greece, Journal of European Social Policy, 21(5), pp. 501-512.

OECD (2013). Education at a Glance 2013: OECD Indicators. Paris: OECD Publishing, 2013. Available at: http://www.oecd.org/edu/eag2013\%20\%28eng\%29--FINAL\%2020\%20June\%202013.pdf (accessed 21/3/2017).

Papadakis, N. (2005), Facets of the employment policies in Greece. Athens: EQUALITY Consortium (G).

Papadakis, N. in cooperation with Drakaki, M., Papargyris, A., Dafermos, V., Basta, M., Theodorikakos, P., Pandis, P., Kyridis A. (2017), "Painted from life...." A disengaged youth? Young people and NEETs in a devastated country. Published by the UCL- Ioe/ Centre for Learning and Life Chances in Knowledge Economies and Societies (LLAKES). London: UCL- IoE/ LLAKES Research Centre (Research Papers Series no 59). Available at: http://www.llakes.ac.uk/sites/default/files/59.\%20Papadakis\%20et\%20al.pdf.

Papadakis, N., Kyridis, A., Papargyris, A. (2015). Searching for absents: The State of things for the NEETs (young people Not in Education, Employment or Training) in Greece. An overview, Journal of Sociological Research, 6 (1), pp. 44-75.

Papadakis, N., Theodorikakos, P., Dafermos, V., Basta, M., Papargyris, A., Drakaki, M. (2016). “Greek Young People not in Education, Employment or Training, in the era of crisis: NEETs' social inclusion/exclusion, employability, civic values and political behavior". Paper presented in the UCL/ LLAKES Research Conference 2016. London: 27 June 2016. Available at: http://www.llakes.ac.uk/event/growing-and-global-austerity-comparing-youthopportunities-aspirations-and-civic-values-around.

Papatheodorou, Ch. \& Papanastasiou S.A. (2010). Intergenerational transmission of poverty in Greece and the EU: Theoretical approaches and empirical analysis, Athens: INE/GSEE (G).

Ralston, K., Feng, Z., Everington, D. \& Dibben, C. (2016). Do young people not in education, employment or training (NEET) experience long term occupational scarring? A longitudinal analysis over 20 years of follow up, Contemporary Social Science, Vol. 11, 2016 - Issue 2-3: Social Inequality. 